\title{
A New Aquatic Nitrogen-Fixing Bacterium from Three Cambridgeshire Chalk Streams
}

\author{
By E. GRAY AND J. D. SMITH \\ The School of Botany and the Molteno Institute, University of Cambridge
}

SUMMARY: A motile rod-shaped bacterium which on nitrogen-free media fixed appreciable quantities of nitrogen gas was isolated in pure culture from three chalk streams near Cambridge. It was weakly Gram-positive and beaded in stained preparations. Flagellation was distinctive and unusual in that the flagella at the poles were coarser than those at the sides. Growth was promoted by sugars, and nitrate was rapidly reduced. Since the flagellation of the organism is unusual, its classification is difficult; but the organism does not appear to have been previously described.

During an investigation of the bacteria of a chalk stream, Hobson's Brook, near Cambridge, a nitrogen-fixing organism was isolated in April 1948, and 2 days later from a mill-pool (Byron's Pool) on the River Cam and about a quarter of a mile away from a second small stream, the Bourn Brook, which empties into Byron's Pool. At that time it was most abundant in Hobson's Brook. The organism was not found in any of these streams during the summer, and no further search was made for it in the Cam or the Bourn Brook. In October 1948 it was again found in some abundance in Hobson's Brook, but not during the winter months. It reappeared, again in some quantity, in Hobson's Brook in the spring of 1949. In Hobson's Brook it was found in greatest abundance in the spring and autumn at certain points where green plants persist all the year round, but this may have no significance.

The organism could not be identified, but as it was thought possible that it might be one of the soil nitrogen-fixing bacteria, a description of it was sent to the Rothamsted Experimental Station. A reply was received stating that it was not one of the known soil forms, and it was suggested that a subculture be sent to Prof. A. J. Kluyver who is at present examining it. The organism has still not been identified. Micrographs taken with the electron microscope by Dr A. L. Houwink have shown that it possesses a most unusual kind of flagellation, which has added further difficulties to the determination of its systematic position.

The three streams from which the organism was first isolated are all alkaline

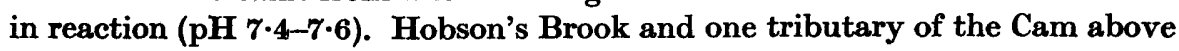
Byron's Pool flow from chalk springs, while the Bourn Brook is derived from surface-water, some of which must originate from the chalk underlying this region of the Cambridge district. All three streams are in the country 3 miles from Cambridge, and flow through arable and old grass-land. They are, however, sharply distinguished by their degrees of turbulence. The Bourn Brook is sluggish, about $8 \mathrm{ft}$. wide and $6 \mathrm{ft}$. deep where the organism was isolated, and flows between banks of soft earth. The Cam enters Byron's Pool over a weir, 
while immediately below the springs the half-mile of Hobson's Brook from which the organism was isolated is swift, shallow and subject to great changes in the volume of water. The bed of this half-mile of Hobson's Brook is composed of alternate stretches of chalk and gravel. Owing to an origin from springs and the swift current, the temperature of Hobson's Brook is lower but more uniform (averaging $10^{\circ}$ all the year round) than that of the Cam or the Bourn Brook, which range between $8^{\circ}$ in winter and $15^{\circ}$ in summer. The amount of dissolved oxygen in Hobson's Brook in the half-mile below the springs is nearly always near saturation; in the Cam and the Bourn Brook it is probably much less owing to the quantity of suspended organic matter.

In Hobson's Brook the organism was found only near three areas where green plants (notably Apium nodiflorum, Veronica anagallis and Nasturtium officinale) exist all the year round. Some unidentified filamentous green algae floated near the point where the organism was found in the Bourn Brook (clear water c. $4 \mathrm{ft}$. from bank). No green plants or algae were present where the organism was taken from the Cam (clear water c. $4 \mathrm{ft}$. from bank).

Method of sampling. Samples were taken from the length of Hobson's Brook and at Byron's Pool and the Bourn Brook, in sterile 8 oz. 'medical flat' bottles having rubber stoppers covered by a cap of Kraft paper. Mannitol (3.0 g.) and $\mathrm{K}_{2} \mathrm{HPO}_{4}(0.2 \mathrm{~g}$.) were added to each bottle before sampling. Samples were taken directly by hand in the current core of Hobson's Brook. The samples from the Bourn Brook and from Byron's Pool were taken from clear water away from banks, by securing the bottles to the end of a rod. The bottles were filled to capacity, restoppered, covered by the Kraft paper cap, and well shaken to dissolve the contents. The temperature of the stream was then taken, and the pH immediately determined colorimetrically on a second sample. On returning to the laboratory, the sample bottles were again well shaken and half their contents poured into sterile plugged $250 \mathrm{ml}$. conical flasks. The remainders of the samples were left in the bottles, whose mouths were plugged with cottonwool.

\section{Method of isolation}

The flasks and bottles were allowed to stand in the shade at $c .15^{\circ}$. After 4-6 days a waxy pellicle appeared on the surface of three samples taken from those points where green plants were found all the year round in Hobson's Brook but not from elsewhere in the Brook, and also on the surface of the samples taken from the Cam and the Bourn Brook. Platinum loopfuls of this pellicle were streaked over the surface of mannitol soil agar medium, and azotobacter (mannitol phosphate agar) medium, and incubated at $22^{\circ}$. The azotobacter medium contained $0.04 \mathrm{~g} . \mathrm{K}_{2} \mathrm{HPO}_{4}, 0.02 \mathrm{~g} . \mathrm{KH}_{2} \mathrm{PO}_{4}, 1.5 \mathrm{~g}$. mannitol, with c. $0 \cdot 1 \mathrm{~g}$. each of $\mathrm{NaCl}, \mathrm{CaCO}_{3}$ and garden soil, with $150 \mathrm{ml}$. distilled water and $2.5 \mathrm{~g}$. washed agar to form a solid medium. After 2 days white opaque pin-point colonies appeared on both media. In one sample from Hobson's Brook, heaped butyrous semi-translucent colonies also appeared on the mannitol soil agar but not on the azotobacter medium. These colonies were subcultured on mannitol soil agar until pure cultures were obtained. The larger 
butyrous colonies were those of an organism identified by Dr E. G. Pringsheim as a species of Monad, a small colourless flagellate. The small white colonies were those of an organism whose description follows.

\section{The organism}

Morphology. A motile rod about 6-8 $\mu$. long. Weakly Gram-positive, showing a beaded appearance suggestive of a diphtheroid. Non-acid-fast when first isolated. Stained by Morton's night blue method, the flagella were peritrichous. Electron micrographs by Dr A. L. Houwink (Delft) showed that the organism had most unusual flagella in that those at the poles appeared coarser than those at the sides. Dr Houwink regards this particular flagellation as remarkable and quite distinctive.

Growth on various media. Although in one instance isolated in association with a colourless flagellate the organism was subsequently maintained alone in pure culture. On all solid media a good growth appeared in 4 days. On mannitol soil agar slopes the colonies were small, thick, white and moist, becoming confluent; on azotobacter medium growth was rather poor, the colonies being opaque, gelatinous and discrete. Similar scattered colonies appeared on plain milk agar and on Yeastrel milk agar. Growth was most profuse on media containing sugar or glycerol. On slopes of Yeastrel glucose agar a moist, diffuse, grey growth with a thick white deposit in the water of condensation appeared. On Yeastrel glycerol agar a similar growth was obtained but white, not grey, in colour. On potato plugs a moist, sticky, confluent growth with a yellow colour was obtained. Gelatin stab cultures (gelatin in Lab-Lemco broth) were not liquefied after 6 weeks, but the medium turned pink. In bouillon (made with Lab-Lemco broth) a faint turbidity with a granular deposit appeared very slowly over 6 weeks. Growth in litmus milk (made with milk powder) was very poor and there was no visible change in the medium after 6 weeks.

Biochemical reactions. Acid but not gas was produced in 2 weeks in peptonefree sugar media containing lactose, maltose, glucose, or sucrose. Salicin was not attacked in 6 weeks. Indole was not produced. The Voges-Proskauer and methyl red reactions were negative; litmus milk was not changed; methylene blue was not reduced. Nitrate was rapidly reduced to nitrite, but ammonia was not formed.

Metabolism. Aerobic, no growth in stab cultures except at surface. Psychrophilic, growing best between $10^{\circ}$ and $20^{\circ}$. Pigment formed. Growth greatly improved by sugar and glycerol. Resistance to heat not determined. Isolated

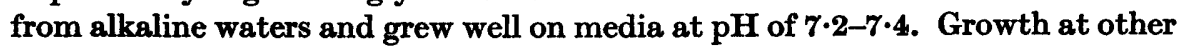
pH values and the calcium requirements were not examined.

Fixation of nitrogen gas. Shortly after isolation the micro-organism was found able to grow in the absence from the medium of combined nitrogen. As the growth observed in media to which no nitrogen compound had been added might have been due to traces of nitrogenous impurities, some preliminary quantitative measurements of the nitrogen gain by growing cultures were made. The nitrogen content of cultures was measured before and after growth by the 
micro-Kjeldahl technique (Markham, 1942). The medium used had the following composition: $\mathrm{K}_{2} \mathrm{HPO}_{4}, 0.8 \mathrm{~g}$.; $\mathrm{KH}_{2} \mathrm{PO}_{4}, 0.2 \mathrm{~g}$.; $\mathrm{NaCl}, 0.2 \mathrm{~g}$.; $\mathrm{MgSO}_{4} .7 \mathrm{H}_{2} \mathrm{O}$, $0 \cdot 2$ g.; $\mathrm{CaSO}_{4} .2 \mathrm{H}_{2} \mathrm{O}, 0 \cdot 1 \mathrm{~g}$; $\mathrm{Fe}_{2}\left(\mathrm{SO}_{4}\right)_{3} \cdot 9 \mathrm{H}_{2} \mathrm{O}$, 0.01 g.; mannitol, $10 \mathrm{~g} . ;$ distilled water to 1 l. (pH 7.3). Sterile $100 \mathrm{ml}$. conical flasks each containing 10 or $15 \mathrm{ml}$. of medium were inoculated with $0.1 \mathrm{ml}$. of a suspension of the bacteria grown on an agar slope of the same medium. Samples $(10 \mathrm{ml}$.) from the flasks were analysed for total nitrogen immediately after inoculation, similar samples being taken from other flasks after incubation at $20^{\circ}$ for several days. Correction was made for any changes in the volume of the contents of the flasks during incubation. The purity of the cultures was examined microscopically at the conclusion of each experiment.

The changes in nitrogen content of these cultures are shown in Table 1. All cultures showed a small increase in nitrogen content which was well outside the limits of experimental error. It was concluded that the micro-organism absorbed small quantities of atmospheric nitrogen (probably limited in these experiments by the rate of diffusion of gas into the medium). The measurements reported are only preliminary ones.

Table 1. Nitrogen content of samples $\left(10 \mathrm{ml}\right.$.) of cultures incubated at $20^{\circ}$

$\begin{array}{llcc} & \begin{array}{c}\text { Nitrogen } \\ \text { Incubation } \\ \text { period }\end{array} & \begin{array}{c}\text { Nitrogen } \\ \text { (mg./10 ml. } \\ \text { culture) }\end{array} & \begin{array}{c}\text { gained } \\ \text { (mg./10 ml. } \\ \text { culture) }\end{array} \\ \text { Exp. 1 } & \begin{array}{c}\text { Zero (control) } \\ \text { Zero (control) }\end{array} & \begin{array}{c}\mathbf{0 . 0 3 6} \\ \mathbf{0 . 0 4 0}\end{array} & - \\ & \text { 4 days } & \mathbf{0 . 0 5 7} & \mathbf{0 . 0 1 9} \\ & \text { 4 days } & \mathbf{0 . 0 6 8} & \mathbf{0 . 0 3 0} \\ \text { Exp. } 2 & \text { Initial sample } & \mathbf{0 . 0 1 0} & - \\ & \text { Initial sample } & \mathbf{0 . 0 1 0} & - \\ & \text { 3 days } & \mathbf{0 . 0 1 9} & \mathbf{0 . 0 0 9} \\ & \text { 3 days } & \mathbf{0 . 0 2 3} & \mathbf{0 . 0 1 3} \\ \text { Exp. 3 (medium with 0.1 \% yeast } & \text { 3 days } & \mathbf{0 . 0 3 2} & \mathbf{0 . 0 2 2} \\ \text { extract added) } & \text { Initial sample } & \mathbf{0 . 0 4 9} & - \\ & \text { 3 days } & \mathbf{0 . 0 6 8} & \mathbf{0 . 0 1 9} \\ & \text { 3 days } & \mathbf{0 . 0 5 7} & \mathbf{0 . 0 0 9} \\ & \text { 3 days } & \mathbf{0 . 0 5 5} & \mathbf{0 . 0 0 6}\end{array}$

Spectroscopic examination. Thick suspensions of the organism were examined by the microspectroscope for evidence of the presence of haematin compounds. On reduction with sodium dithionite the absorption bands of the cytochromes were immediately visible. These appeared to be identical with those observed in suspensions of various strains of Rhizobium. The $\alpha$ bands of cytochromes $a, b$ and $c$ could be distinguished; those of cytochromes $b$ and $c$ were extremely close together but were easily resolved on cooling to liquid air temperature.

We wish to thank Dr A. L. Houwink for permission to reproduce the electron micrographs. 
Journal of General Microbiology, Vol. 4, No. 3

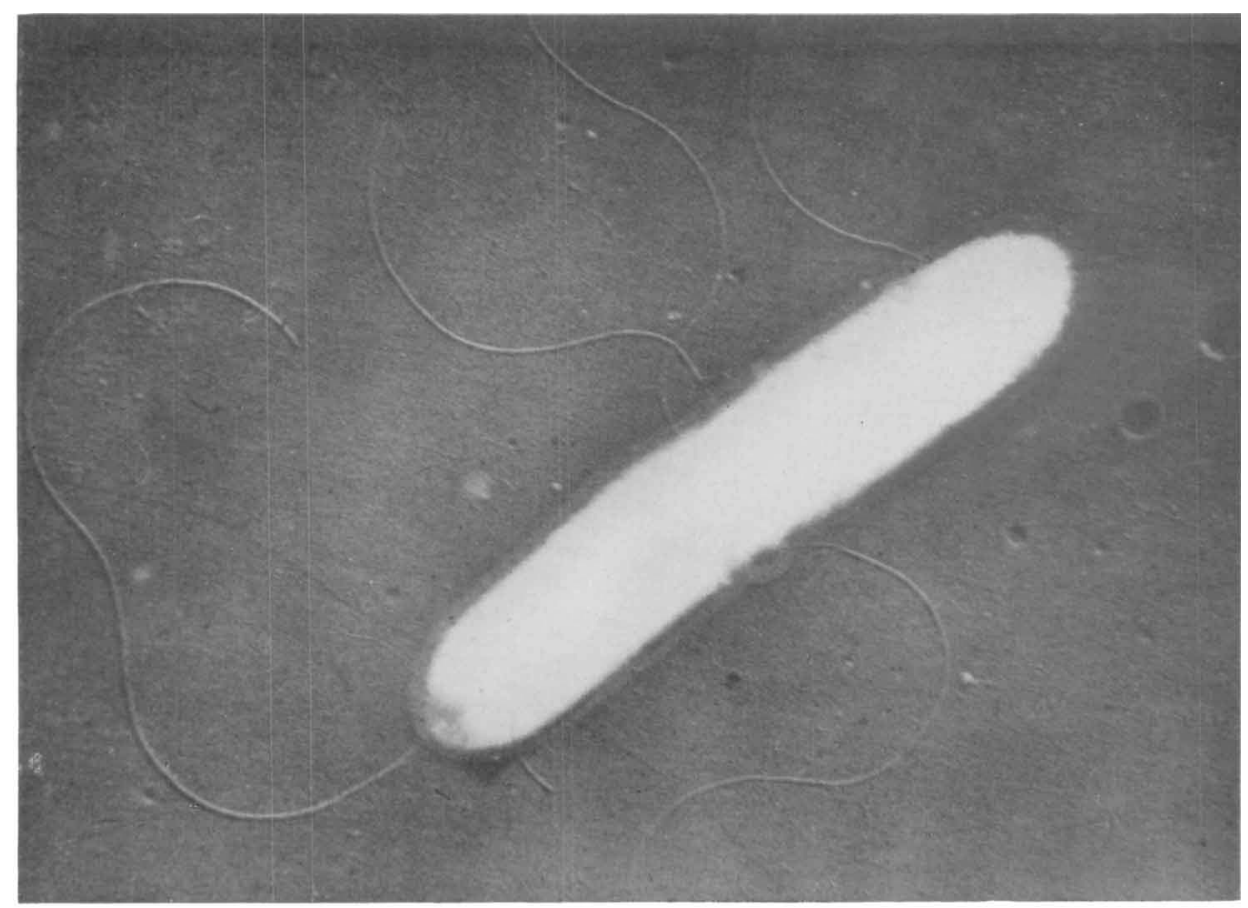

Fig. 1

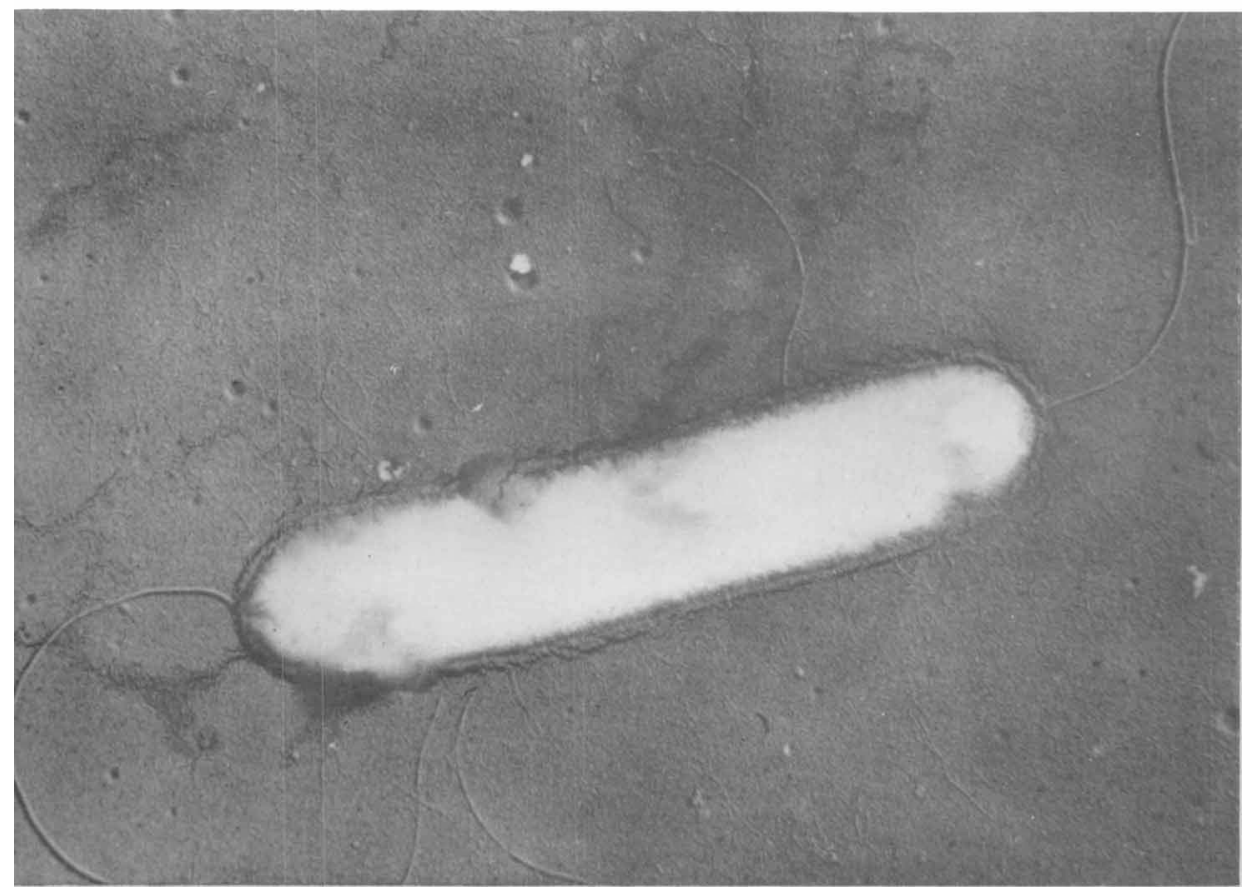

Fig. 2

E. Gray \& J. D. Smith-A New aquatic nitrogen-fixing bacterium from three Cambridgeshire chalk streams. Pt.atw. 1 


\section{REFERENCES}

Markham, R. (1942). A steam distillation apparatus suitable for micro-Kjeldahl analysis. Biochem. J. 36, 790.

\section{EXPLANATION OF PLATE}

Figs. $I$ and 2. Micro-photographs of the organism taken with the electron microscope by Dr A. L. Houwink. The distinctive flagellation, coarser at the poles than at the sides, is shown.

(Received 15 October 1949) 